Original article

\title{
Age of onset and quality of life among males and females with schizophrenia: A national study
}

\author{
Anat Rotstein*, David Roe, Marc Gelkopf, Stephen Z. Levine \\ Department of Community Mental Health, Faculty of Social Welfare and Health Sciences, University of Haifa, Haifa 3498838, Israel
}

\section{A R T I C L E I N F O}

\section{Article history:}

Received 14 April 2018

Received in revised form 12 June 2018

Accepted 13 June 2018

Available online 27 June 2018

\section{Keywords:}

Schizophrenia

Epidemiology

Psychometric

Male female differences

Competing models

\begin{abstract}
A B S T R A C T
Background: Age of onset is considered central to understanding the course of schizophrenia, yet little is known regarding its association with quality of life in general, and specifically among males and females.

Aims: To examine the association between the age of schizophrenia onset and quality of life, in general, and among males and females, using data from a national sample and competing statistical models. Methods: Participants with a diagnosis of schizophrenia $(\mathrm{N}=1624)$ completed the Manchester Short Assessment of Quality of Life (MSA-QoL) and were rated on a parallel measure by their professional caregivers $(\mathrm{N}=578)$. Multiple regression analysis models were computed for self-appraised quality of life, and mixed models with random intercepts were used for caregivers. Six competing models were tested for parsimony for each rating source. Three models without adjustment and three models adjusted for confounding variables. Sensitivity analyses were conducted for males and females separately.

Results: Age of onset was statistically significantly $(\mathrm{P}<.05)$ negatively associated with self-appraised and caregiver-appraised quality of life on aggregate and among females. Among males, a significant $(\mathrm{P}<.01)$ quadratic effect of onset age on self-appraised quality of life demonstrated a negative association up to onset age of 36.67 years, after which the association was positive.

Conclusions: An earlier age of onset is associated with a better quality of life in schizophrenia which is tentatively explained by social decline. Specific trends in psychiatric symptom severity may account for this association among females while social advantages may account for the particular results found among males.
\end{abstract}

(c) 2018 Elsevier Masson SAS. All rights reserved.

\section{Introduction}

Age of onset is considered central to understanding the course of schizophrenia [1]. An earlier age of onset is associated with a worse course of the disorder and with poorer outcomes, including a worse course of psychiatric hospitalization in the long and short term [2], poorer educational and vocational adjustment [3], lower levels of social functioning and social cognition [4], and an increased risk of suicide [5].

In contrast with most studies which reported that an earlier age of onset is associated with worse outcomes [2-5], many studies report that age of onset is unrelated to quality of life [6-10], a relevant outcome in schizophrenia [6,11]. Quality of life has

\footnotetext{
* Corresponding author.

E-mail addresses: aharshko@campus.haifa.ac.il (A. Rotstein), droe@univ.haifa.ac.il (D. Roe), mgelkopf@univ.haifa.ac.il (M. Gelkopf), slevine@univ.haifa.ac.il (S.Z. Levine).
}

developed into a central concept in mental health care [12-15] as treatment goals shifted from symptom change to incorporate recovery outcomes evaluating a personally meaningful life [16,17]. Quality of life and symptom severity only moderately correlated [18-22] and so represent alternative approaches to outcome assessment. One approach views recovery as a subjective process while a contrasting approach defines recovery as an objective outcome [23]. These contrasting approaches may account for the aforementioned particular results of a null association between age of onset and quality of life. Nonetheless, one study reported that early onset mediated associations with quality of life [24], indicating that age of onset played a secondary role in quality of life. Thus a further examination of the role of age of onset on quality of life is needed.

The association between age of onset and quality of life is yet to be explored among males and females. Being female has been previously linked to lower quality of life in schizophrenia [25], while being male has been linked to an earlier onset of schizophrenia [26,27] and poorer outcomes [26,28,29]. These 
aforementioned findings may be accounted for by the distinctive nature of the association between age of onset and quality of life or by specific trends of this association, differentiating males and females.

Research suggests that mental health patients and professional caregivers usually appraise quality of life by relying on different aspects [30-32]. Appraisals by professional caregivers are mostly based on psychiatric symptoms, whereas patients base their appraisals on physical health and social relations [30,31]. Disparities between different rating sources are highly prevalent in studies of quality of life [13,30-,31,32,33,34,35,36]. Hence both self-appraised and caregiver-appraised quality of life scores should be considered for robustness.

The current study aims to examine the association between the age of onset and quality of life, among males and females with schizophrenia, using a national study design with competing statistical models. The current study hypotheses are that age of onset would positively correlate with self-appraised and caregiverappraised quality of life, and that this correlation would be amplified among males.

\section{Methods}

\subsection{Participants}

In this ongoing study, the current cohort was part of the Psychiatric Rehabilitation Routine Outcome Measurement Project [37]. The study was approved by the Helsinki committee at the Ministry of Health and by the Institutional Review Board at the University of Haifa. Assessments were conducted during psychiatric rehabilitation and were supervised by an internal service staff member or externally trained individuals [38].

The current study included a subset of persons with a last diagnosis of schizophrenia who had information on birth year, dates of psychiatric hospital admissions and self and caregiverappraised quality of life assessments $(\mathrm{N}=1624)$. All participants received national psychiatric rehabilitation services in Israel. The exclusion criteria for psychiatric rehabilitation services are illicit drug addiction, violence and lack of psychiatric monitoring. Participants completed the research questionnaires from January $1^{\text {st }}, 2013$ to August $19^{\text {th }}, 2015$. Professional caregivers $(N=578)$ were given instruments that mirrored the one designed for selfappraisals.

\subsection{Data sources}

Demographic data (e.g. birth year), hospitalization information (e.g. date and duration of first and subsequent psychiatric hospital admissions) and psychiatric diagnosis were obtained from the Israeli National Psychiatric Case Registry. The registry, established in 1950, contains a lifelong listing of psychiatric hospitalizations in Israel, and includes ICD-10 diagnoses made by an Israeli medical board certified psychiatrist. Registry diagnoses include almost all persons with schizophrenia [39], were found to be reliable over time [40], and have acceptable sensitivity compared to research diagnostic criteria [41]. The registry has been used in numerous studies $[2,42,43]$.

\subsection{Quality of life appraisal}

Mental health related quality of life was measured and validated [37] based on the Manchester Short Assessment of Quality of Life (MSA-QoL), an abbreviated version of the Lancaster Questionnaire Life Quality Profile [44]. Scale items were rated on a 5-point Likert scale and coded so higher scores on the assessment indicated better quality of life. Eight items measured satisfaction with one's work or volunteering activities, financial status, social status and activities, family relations, leisure activities, residential status, physical health condition and mental health condition (one item per life area). Quality of life appraisals for persons with schizophrenia were made by two rating sources: self-appraised and by their professional caregivers. Caregivers were given an instrument that mirrored the one designed for self-appraisals. The internal reliabilities of the measure were acceptable for self and caregiver-appraisals ( $\alpha=0.76 ; \alpha=0.77$, respectively).

\subsection{Analytic approach}

First, descriptive analyses were computed of the sample characteristics. A modest yet statistically significant correlation was observed between self-appraised and caregiver-appraised quality of life $(r=0.29, p<0.01)$, like prior research [30-36]. Mean scores were significantly $(t(1623)=24.01, \mathrm{p}<.05)$ higher for selfappraisals $(\mathrm{M}=28.86, \mathrm{SD}=5.59)$ compared to caregiver appraisals $(\mathrm{M}=25.12, \mathrm{SD}=4.89)$, like prior research [36]. Hence, selfappraised and caregiver-appraised quality of life scores were analyzed for robustness.

Second, the primary statistical analysis examined the association between self-appraised and then caregiver-appraised quality of life as a function of age of onset using regression models. The assumptions of the regression models were tested. Visual inspection of residual figures was performed in order to reveal deviations from homoscedasticity or normality. An inspection for normality of error terms followed using a histogram and probability plots of the residuals. Independence of the error term was examined through a scatter plot of residuals by the predicted values to show that no discernible association existed. Then, statistically significant outliers were removed as their inclusion offsets estimation [45]. Next, multiple regression analysis models were computed for self-appraised quality of life. Mixed models with random intercepts for caregivers were then used to account for the repeated caregiver ratings in the data. Significance for mixed regression models was calculated by comparing models via the likelihood ratio test.

Competing models for each rating source were computed in ascending complexity and tested without adjustment and adjusted for confounding of birth year, age at the time of data collection, duration of disorder and whether male or female. The age of onset was derived from the difference between the date of birth and date of first psychiatric hospital admission. Duration of disorder was derived from the difference between the time of data collection and the date of first psychiatric hospital admission and was categorized into four categories cased on quartile scores. Age at the time of data collection was derived from the difference between the time of data collection and the date of birth and was categorized into two categories based on the median score. Birth year was categorized into two categories based on the median score. Models for each rating source were numbered as follows. The first model accounted for a linear effect of age of onset on selfappraised quality of life (model 1 hereafter). The second model accounted for a linear effect of age of onset, whether male or female, birth year, age at the time of data collection and duration of disorder (model 2 hereafter). The third model accounted for a quadratic effect of age of onset on self-appraised quality of life (model 3 hereafter). The fourth model accounted for a quadratic effect of age of onset, whether male or female, birth year, age at the time of data collection and duration of disorder (model 4 hereafter). The fifth model accounted for a cubic effect of age of onset on self-appraised quality of life (model 5 hereafter). The sixth model accounted for a cubic effect of age of onset, whether male or female, birth year, age at the time of data collection and duration of disorder (model 6 hereafter). 
Third, models for each rating source were compared for parsimony based on the Bayesian Information Criterion (BIC) for model selection [46], similar to prior research [47,48]. Lower BIC values represent more parsimonious models and so are a better fit to the data.

In instances of quadratic models, the cutoff point was computed by setting the second derivative equal to zero [49]. Since an upward concave corresponds to a positive second derivative and downward concave corresponds to a negative second derivative, then when the function changes from upward concave to downward concave (or vice-versa) the second derivative equals to zero.

Sensitivity analyses were conducted for males and females, like in prior research [2]. All regression models were recomputed separately for males and females and then compared for parsimony.

All analyses were computed in R [50] with the lme4 library [51] used to compute linear mixed effects of the associations between caregiver-appraised quality of life and age of onset.

\section{Results}

\subsection{Sample characteristics}

The final sample was based on 1551 persons with schizophrenia rated by 564 professional caregivers. This sample size was a result of removing all outliers $(\mathrm{N}=73,4.5 \%)$. Of the remainder a total of $62 \%(N=957)$ of the participants were males $(N=594$ females $)$. Overall mean age for first psychiatric hospital admission was 25.55 years $(S D=8.32), 26.13$ years $(S D=8.91)$ for females, and 25.18 years $(S D=7.92)$ for males. Overall mean birth year was 1967 $(\mathrm{SD}=12.03$ years; mean age at time of data collection was 46.5 years), for females 1966 ( $\mathrm{SD}=12.13$ years; mean age at time of data collection was 47.84 years), and for males 1968 ( $\mathrm{SD}=11.90$ years; mean age at time of data collection was 45.66 years). Overall mean duration of disorder was 21.05 years $(S D=11.72), 21.81$ years $(S D=12.02)$ for females, and 20.58 years $(S D=11.52)$ for males. See Table 1 for mean and $95 \%$ confidence interval values of quality of life appraisals and age of onset.

Among the caregivers, 44\% $(\mathrm{N}=249)$ appraised one person with schizophrenia, $21 \%(\mathrm{~N}=120)$ appraised two persons, $11 \%(\mathrm{~N}=61)$ appraised three persons, and $24 \%(\mathrm{~N}=134)$ appraised four or more persons.

\subsection{Primary statistical analysis}

\subsubsection{Self-appraised quality of life as a function of age of onset}

Comparison of the six competing regression models showed that model 1 was the most parsimonious (BIC=9573.99; Table 2; See Table 3 for comparison of BIC values for all self-appraised quality of life models). This model indicated that age of onset alone was significantly $(\mathrm{P}<.01)$ negatively associated with self-appraised quality of life (Fig. 1a).

Table 1

Mean and 95\% confidence interval values of quality of life and age of onset.

\begin{tabular}{llll}
\hline & Total Sample & Females & Males \\
& $\mathrm{N}=1551$ & $\mathrm{~N}=594$ & $\mathrm{~N}=957$ \\
\hline & Age of Onset & & \\
Mean (SD) & $25.55(8.32)$ & $26.13(8.91)$ & $25.18(7.92)$ \\
95\% confidence interval values & $25.13,25.96$ & $25.41,26.85$ & $24.68,25.69$ \\
& Self-appraised quality of life & \\
Mean (SD) & $28.85(5.59)$ & $28.56(5.63)$ & $29.03(5.56)$ \\
95\% confidence interval values & $28.57,29.13$ & $28.11,29.01$ & $28.68,29.38$ \\
& Caregiver-appraised quality of life \\
Mean (SD) & $25.08(4.88)$ & $24.96(4.96)$ & $25.15(4.82)$ \\
95\% confidence interval values & $24.83,25.32$ & $24.56,25.37$ & $24.84,25.45$ \\
\hline
\end{tabular}

Table 2

Best-fitting quality of life model parameters.

\begin{tabular}{lcllll}
\hline Model & Estimates & SE & T & P & BIC \\
\hline Self-appraised quality of life models & & & & \\
Model 1: Intercept & 30.33 & 0.46 & 66.53 & $<0.01$ & 9573.99 \\
Age of Onset & -0.06 & 0.02 & -3.40 & $<0.01$ & \\
Model 1- F : Intercept & 30.29 & 0.71 & 42.46 & $<0.01$ & 3750.57 \\
Age of Onset & -0.07 & 0.03 & -2.56 & 0.01 & \\
Model 3- M: Intercept & 35.35 & 1.85 & 19.06 & $<0.01$ & 6012.84 \\
Age of Onset & -0.44 & 0.14 & -3.20 & $<0.01$ & \\
Quadratic Age of Onset & 0.01 & 0.002 & 2.88 & $<0.01$ & \\
Caregiver-appraised quality of life models & & & \\
Model 1 : Intercept & 25.82 & 0.40 & 64.13 & $<0.01$ & 9291.33 \\
Age of Onset & -0.03 & 0.01 & -2.11 & 0.04 & \\
Model 1- F : Intercept & 26.30 & 0.64 & 41.35 & $<0.01$ & 3607.00 \\
Age of Onset & -0.05 & 0.02 & -2.40 & 0.02 & \\
\hline
\end{tabular}

Self-appraised quality of life models:

Model 1: Self-appraised quality of life $=$ Intercept + Age of Onset.

Model 1- F: Female self-appraised quality of life $=$ Intercept + Female Age of Onset. Model 3- M: Male self-appraised quality of life = Intercept + Male Age of Onset + (Male Age of Onset) ${ }^{2}$

Caregiver-appraised quality of life models:

Model 1: Caregiver-appraised quality of life = Intercept + Age of Onset.

Model 1- F: Caregiver-appraised female quality of life = Intercept + Female Age of Onset.

3.2.2. Caregiver-appraised quality of life as a function of age of onset Comparison of the six competing linear mixed effect models showed that model 1 was the most parsimonious (BIC $=9291.33$; Table 2; See Table 3 for comparison of BIC values for all caregiverappraised quality of life models). This model accounted for a linear effect of age of onset on caregiver-appraised quality of life, beyond the effect of each individual caregiver (Fig. 2a) and indicated that age of onset alone was significantly $(\mathrm{P}<.05)$ negatively associated with caregiver-appraised quality of life.

\subsection{Sensitivity analysis: age of onset and quality of life among males and females}

All aforementioned models were recomputed separately for males and females (see Table 3 for BIC values). Consistent with the results of the primary analysis, among females with schizophrenia, for self-appraised quality of life, model 1 (a linear effect of age of onset on self-appraised quality of life) was the best fitting model (BIC = 3750.57; Table 2; Fig. 1b). Among males with schizophrenia, model 3 was the best fitting model (BIC $=6012.84$; Table 2; Fig. 1c). Model 3 consisted of a quadratic effect of age of onset alone on selfappraised quality of life, inconsistent with the linear effect found for the total sample. This model had an inflection point, in which the curve changed from being concave downward to being concave upward, at onset age of 36.67 years.

The unique effects of males and females were also found for the mixed models (see Table 3 for BIC values). Consistent with the primary analysis, among females with schizophrenia, for caregiver-appraised quality of life, model 1 (a linear effect of age of onset beyond the effect of individual caregivers, on caregivers' appraisals of quality of life) was the best fitting model (BIC $=3607.00$; Table 2; Fig. 2b). Among males with schizophrenia, age of onset could not significantly predict caregiver-appraised quality of life, using any of the mixed models described (see Fig. 2c), a result which was inconsistent with the linear effect found for the total sample.

\section{Discussion}

The current study examined the association between the age of onset and quality of life, among males and females with schizophrenia, using data from a national sample and competing 
Table 3

BIC values for self-appraised and caregiver-appraised quality of life models.

\begin{tabular}{|c|c|c|c|}
\hline Models compared & $\begin{array}{l}\text { Total sample } \\
\text { self-appraised quality of life BIC }\end{array}$ & $\begin{array}{l}\text { Female sample } \\
\text { self-appraised quality of life BIC }\end{array}$ & $\begin{array}{l}\text { Male sample } \\
\text { self-appraised quality of life BIC }\end{array}$ \\
\hline Model 1 & 9749.41 & 3750.57 & 6014.24 \\
\hline Model 2 & $\overline{9775.76}$ & $\overline{3768.26}$ & 6034.66 \\
\hline Model 3 & 9753.80 & 3756.83 & 6012.84 \\
\hline Model 4 & 9779.71 & 3774.45 & $\overline{6032.83}$ \\
\hline Model 5 & 9760.86 & 3763.18 & 6019.69 \\
\hline Model 6 & 9786.77 & 3780.77 & 6039.68 \\
\hline Models compared & $\begin{array}{l}\text { Total sample } \\
\text { caregiver-appraised quality of life BIC }\end{array}$ & $\begin{array}{l}\text { Female sample } \\
\text { caregiver-appraised quality of life BIC }\end{array}$ & $\begin{array}{l}\text { Male sample } \\
\text { caregiver-appraised quality of life BIC }\end{array}$ \\
\hline Model 1 & 9291.33 & 3607.00 & 5727.19 \\
\hline Model 2 & $\overline{9304.84}$ & $\overline{3618.23}$ & $\overline{5737.30}$ \\
\hline Model 3 & 9307.77 & 3623.15 & 5743.99 \\
\hline Model 4 & 9321.75 & 3634.64 & 5754.30 \\
\hline Model 5 & 9330.68 & 3644.07 & 5766.00 \\
\hline Model 6 & 9344.80 & 3655.64 & 5776.32 \\
\hline
\end{tabular}

Note: The lowest BIC is the best-fitting model and is underlined for clarity.

Self-appraised quality of life models:

Model 1: Self-appraised Quality of Life = Intercept + Age of Onset.

Model 2: Self-appraised Quality of Life = Intercept + Age of Onset + Birth year + Duration of disorder + Age.

Model 3: Self-appraised Quality of Life $=$ Intercept + Age of Onset $+(\text { Age of Onset })^{2}$.

Model 4: Self-appraised Quality of Life $=$ Intercept + Age of Onset $+(\text { Age of Onset })^{2}+$ Birth year + Duration of disorder + Age

Model 5: Self-appraised Quality of Life $=$ Intercept + Age of Onset $+(\text { Age of Onset })^{2}+(\text { Age of Onset })^{3}$.

Model 6: Self-appraised Quality of Life $=$ Intercept + Age of Onset $+(\text { Age of Onset })^{2}+(\text { Age of Onset })^{3}+$ Birth year + Duration of disorder + Age

Model 2, model 4 and model 6 for the total sample were also adjusted for being male or female.

Caregiver-appraised quality of life models:

Model 1: Caregiver-appraised Quality of Life = Intercept + Age of Onset.

Model 2: Caregiver -appraised Quality of Life = Intercept + Age of Onset + Birth year + Duration of disorder + Age.

Model 3: Caregiver -appraised Quality of Life $=$ Intercept + Age of Onset $+(\text { Age of Onset })^{2}$.

Model 4: Caregiver -appraised Quality of Life $=$ Intercept + Age of Onset $+(\text { Age of Onset })^{2}+$ Birth year + Duration of disorder + Age

Model 5: Caregiver -appraised Quality of Life $=$ Intercept + Age of Onset $+(\text { Age of Onset })^{2}+(\text { Age of Onset })^{3}$.

Model 6: Caregiver -appraised Quality of Life $=$ Intercept + Age of Onset $+(\text { Age of Onset })^{2}+(\text { Age of Onset })^{3}+$ Birth year + Duration of disorder + Age

Model 2, model 4 and model 6 for the total sample were also adjusted for being male or female.
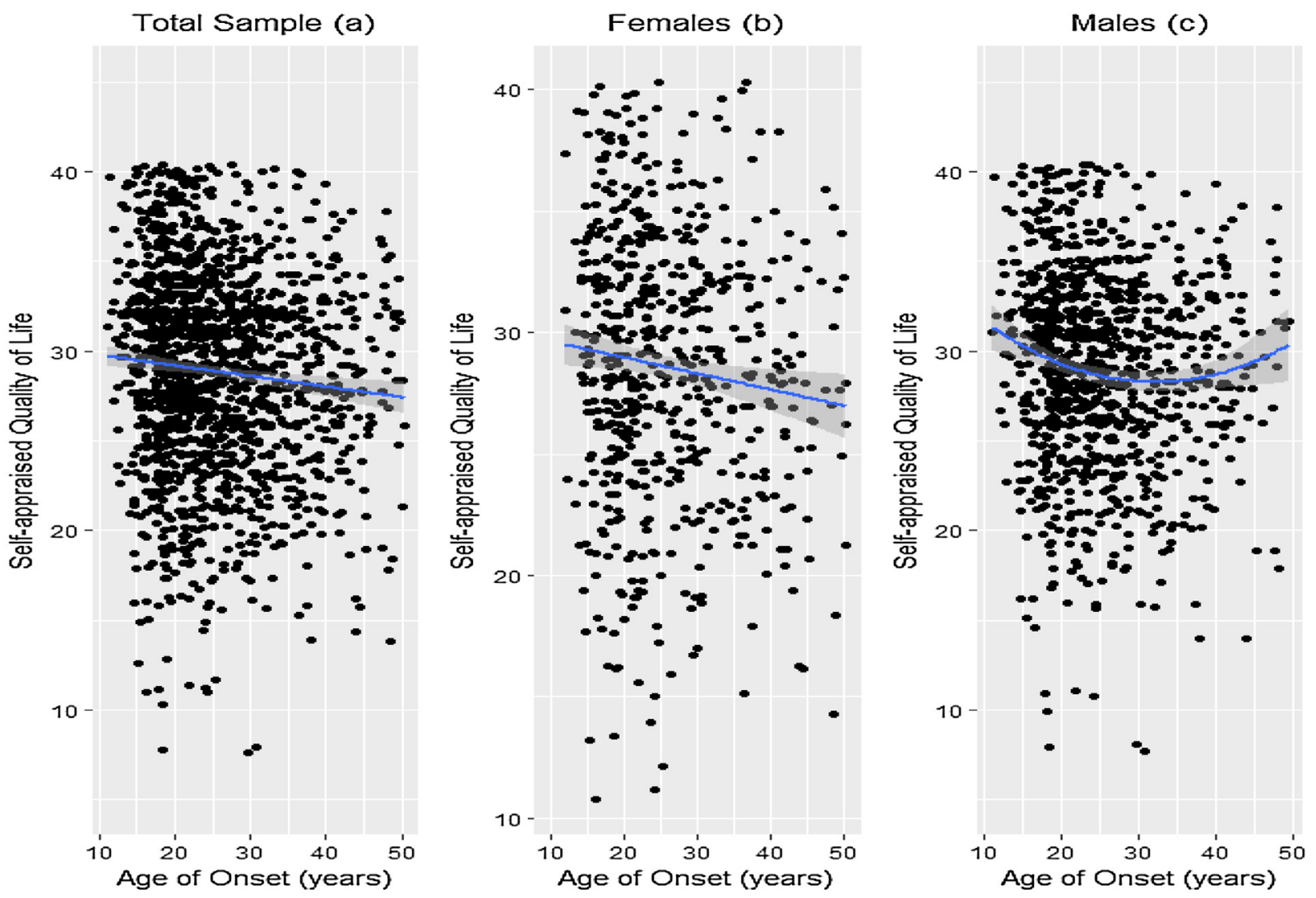

Fig. 1. Self-appraised quality of life as a function of age of onset.

Note: The slope in figure 1a is based on Model 1 (Self-appraised quality of life=Intercept + Age of Onset).

The slope in figure $1 \mathrm{~b}$ is based on Model 1 for females (Self-appraised female quality of life=Intercept + Female Age of Onset).

The slope in figure $1 \mathrm{c}$ is based on Model 3 for males (Self-appraised male quality of life =Intercept + Male Age of Onset $+\left(\right.$ Male Age of Onset) ${ }^{2}$. 

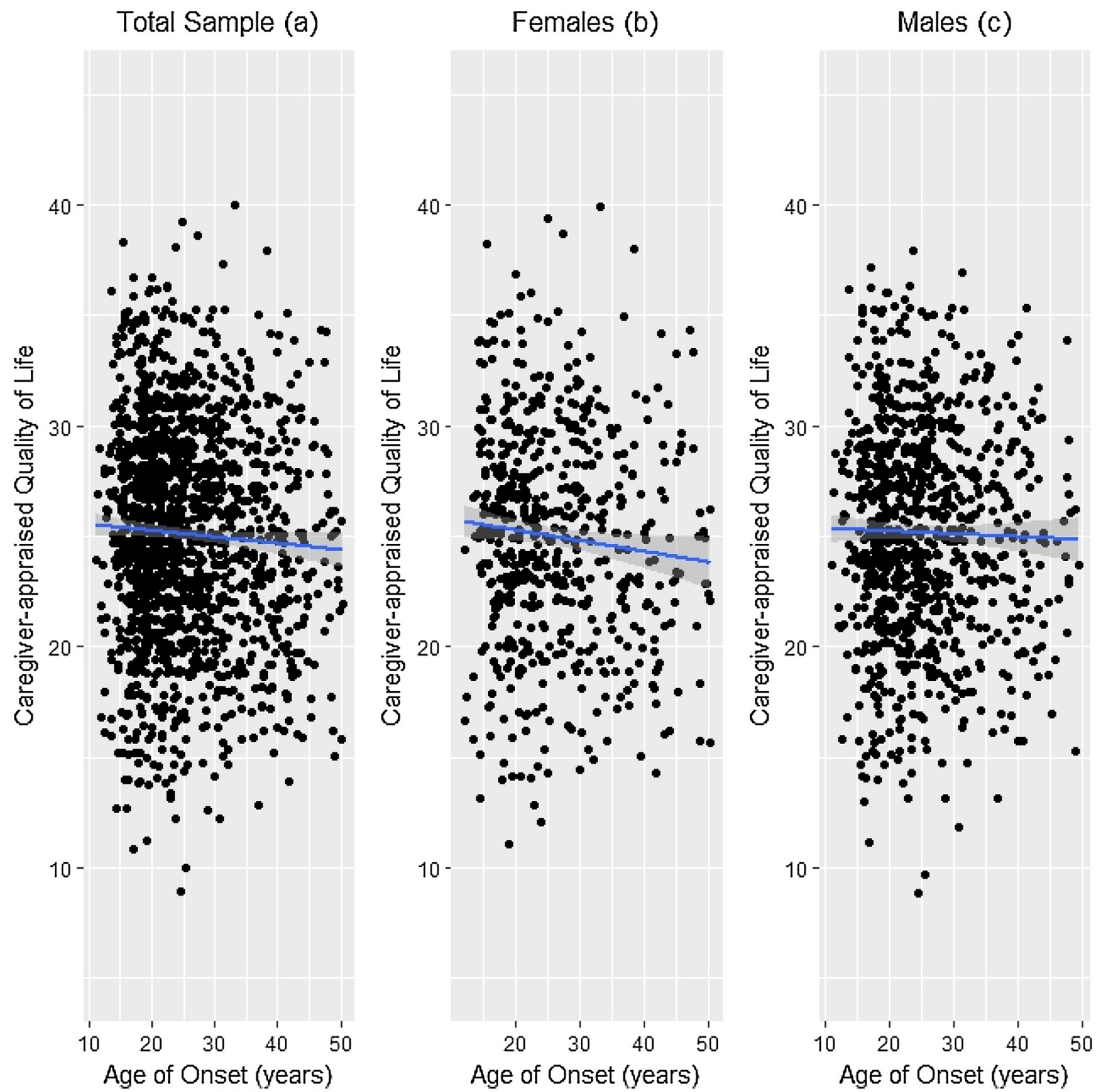

Fig. 2. Caregiver-appraised quality of life as a function of age of onset.

Note: The slope in figure $2 a$ is based on Model 1 (Caregiver-appraised quality of life =Intercept + Age of Onset).

The slope in figure $2 b$ is based on Model 1 for females (Caregiver-appraised female quality of life = Intercept Female Age of Onset).

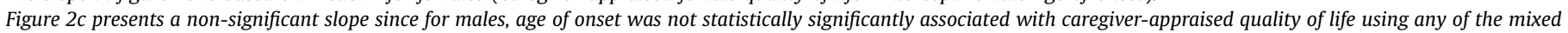
models computed.

statistical models. Results show that self-appraised or caregiverappraised quality of life decreased as age of onset increased, contrary to the study hypothesis of a positive correlation.

The current study result that age of onset is negatively associated with quality of life in schizophrenia, may seem incongruent with much research claiming that earlier onset age is associated with poorer outcomes [2]. Nonetheless, quality of life differs in its experience [6] compared to the other outcomes (e.g., the course of psychiatric hospitalizations) that have been examined for their association with age of onset. Taken together with prior research, social decline may tentatively explain the reported tendency to generally appraise lower quality of life as the age of onset increases [52-56].

Similarly, the current findings show that for females with schizophrenia, quality of life appraisals decreased as the age of onset increased. Some earlier evidence suggests that a unique trend for females may be accounted for by psychiatric symptom severity. Late-onset females with schizophrenia (but not males) were found to have a general negative symptoms score more unfavorable than early-onset females [53,57], perhaps due to a reduced protective effect of estrogen [54]. Psychiatric symptoms were steadily found to be negatively related to quality of life (see meta-analysis (18)) and their severity may tentatively explain the progressing decrease in female quality of life.

Finally, among males, results showed a quadratic effect of onset age on self-appraised quality of life, contrary to the study hypothesis that the positive correlation between onset age and quality of life would be amplified. The quadratic effect demonstrated a negative association up to onset age of 36.67 years, after which the association was positive. The age of 36 has been 
observed to distinguish early and late onset [58] and confer to a reduced risk of suicide, especially for males [59]. The positive association between age of onset and quality of life among males after the age of 36.67 may reflect the higher chances of retaining acquired social advantages associated with later onset [53]. Male onset age was not associated with caregiver-appraised quality of life, suggesting that the association is not robust like previously discussed, and that disparities between different rating sources largely exist for males.

\section{Limitations}

The current results are based on an abridged version of the MANSA [44]. More recent and broader quality of life measures exist that may yield different trends. Further, the underlying concept of quality of life in this questionnaire is generic and not disorderspecific. The measure, however, was chosen for pragmatic reasons of time and administration to a large sample [60]. Additionally, although past studies suggest that information from patients is no less valid than data from other sources [61], the current data consist of two quality of life rating sources which enable greater confidence than had a single data source been used. Finally, quality of life was appraised by different sources than those from which onset age was derived, and there was a difference of 21.05 years (on average, $\mathrm{SD}=11.72$ ) between the actual age of onset and the time of assessment completion. Still, future research is warranted to ensure that the results generalize to other tools and samples.

Other than date of first psychiatric hospital admission, different age of onset measures, such as age when behavioral changes begin to occur or age at first manifestation of positive symptoms (e.g.(1)), were not available. However, past research indicates that there is close correspondence between different onset definitions [62,63].

Furthermore, a longer duration of untreated psychosis, which was not measured in the current study, cannot be ruled out as an explanation of the association found in this study. Indeed, other research has reported a moderate yet significant correlation between duration of untreated psychosis and onset age [64,65].

Similarly, the current study did not consist of information on the psychiatric symptoms of schizophrenia disorder (e.g., the PANSS [66]) and specifically on negative symptoms which were found integral to quality of life $[53,57]$. We were therefore unable to learn of the actual interplay between symptoms, age of onset and quality of life, among males and females. Future studies may look into these associations.

\section{Summary}

This is the first study to examine competing statistical models of the association between quality of life appraisals and age of onset using a national study design. Age of onset was significantly associated with quality of life in schizophrenia, whether self-appraised or caregiverappraised, and this association differed among males and females. Quality of life appraisals decreased as the age of onset increased for the general sample and for females. For males, a quadratic association was found between age of onset and self-appraised quality of life. Results may be tentatively explained by mechanisms of social decline, social advantages and symptomatology.

\section{Funding}

This publication is based on the results of the Outcomes Project that was conducted by Professor David Roe and Professor Marc Gelkopf of The Center for Mental Health Research, Practice and Policy at the Department of Community Mental Health with joint funding from the Israeli Ministry of Health and the Laszlo N. Tauber Family Foundation.

\section{Conflict of interest}

None. The authors report no conflict of interest in the past three years and are responsible for the content and writing of the paper.

\section{Contributors}

Author Anat Rotstein wrote the publication study protocol, managed the literature searches, conducted the statistical analysis and wrote the first draft of the manuscript. Authors Anat Rotstein and SZL designed the publication study protocol. All authors provided critical statistical and manuscript feedback. All authors contributed to and approved the final manuscript.

\section{Acknowledgements}

We are grateful acknowledge for the ongoing collaboration with the Mental Health Rehabilitation Department, especially Ronit Dudai and Vered Balush, and the Department of Information and Evaluation at the Ministry of Health, especially Rinat Yoffe as well as the entire team of the Psychiatric Rehabilitation Patient Reported Outcome Measurement project, notably Aid Rohanna, Paula Garber, Adi Telem and Ronit Mirkin. We acknowledge with thanks the support of The Center for Mental Health Research, Practice and Policy at the University of Haifa.

\section{References}

[1] DeLisi L.E.. The significance of age of onset for schizophrenia. Schizophr Bull 1992:18(2):209-15.

[2] Rabinowitz J, Levine SZ, Häfner H. A population based elaboration of the role of age of onset on the course of schizophrenia. Schizophr Res 2006;88(1):96-101.

[3] Lay B, Blanz B, Hartmann M, Schmidt MH. The psychosocial outcome of adolescent-onset schizophrenia: a 12-year followup. Schizophr Bull 2000;26 (4):801-16.

[4] Linke M, Jankowski KS, Ciołkiewicz A, Jedrasik-Styła M, Parnowska D, Gruszka A, et al. Age or age at onset? which of them really matters for neuro and social cognition in schizophrenia?. Psychiatry Res 2015;225(1):197-201.

[5] Kuo C, Tsai S, Lo C, Wang Y, Chen C. Risk factors for completed suicide in schizophrenia. J Clin Psychiatry 2005;66(5):579-85.

[6] Heinrichs DW, Hanlon TE, Carpenter [131_TD\$DIFF]Jr WT. The quality of life scale: an instrument for rating the schizophrenic deficit syndrome. Schizophr Bull 1984;10(3):388-98.

[7] Browne S, Roe M, Lane A, Gervin M, Morris M, Kinsella A, et al. Quality of life in schizophrenia: relationship to sociodemographic factors, symptomatology and tardive dyskinesia. Acta Psychiatr Scand 1996;94(2):118-24.

[8] Browne S, Clarke M, Gervin M, Waddington JL, Larkin C, O'callaghan E. Determinants of quality of life at first presentation with schizophrenia. The British Journal of Psychiatry 2000;176(2):173-6.

[9] Ritsner M. Predicting changes in domain-specific quality of life of schizophrenia patients. J Nerv Ment Dis 2003;191(5):287-94.

[10] Bellino S, Rocca P, Patria L, Marchiaro L, Rasetti R, Di Lorenzo R, et al. Relationships of age at onset with clinical features and cognitive functions in a sample of schizophrenia patients. J Clin Psychiatry 2004;65(7):908-14.

[11] Strauss JS, Breier A. The vermont longitudinal study of persons with severe mental illness, II: Long-term outcome of subjects who retrospectively met DSM-III criteria for schizophrenia. Am J Psychiatry 1987:144:727.

[12] Mashiach-Eizenberg M, Hasson-Ohayon I, Yanos PT, Lysaker PH, Roe D. Internalized stigma and quality of life among persons with severe mental illness: the mediating roles of self-esteem and hope. Psychiatry Res 2013;208 (1):15-20.

[13] Voruganti L, Heslegrave R, Awad A, Seeman M. Quality of life measurement in schizophrenia: reconciling the quest for subjectivity with the question of reliability. Psychol Med 1998;28(01):165-72.

[14] Lasalvia A, Bonetto C, Malchiodi F, Salvi G, Parabiaghi A, Tansella M, et al Listening to patients' needs to improve their subjective quality of life. Psychol Med 2005;35(11):1655-65.

[15] Boyer L, Baumstarck K, Boucekine M, Blanc J, Lançon C, Auquier P. Measuring quality of life in patients with schizophrenia: an overview. Expert Rev Pharmacoecon \& Outcomes Res 2013;13(3):343-9.

[16] Liberman RP, Kopelowicz A, Ventura J, Gutkind D. Operational criteria and factors related to recovery from schizophrenia. Int Rev Psychiatry 2002;14 (4):256-72.

[17] Priebe S. Social outcomes in schizophrenia. Br J Psychiatry 2007;191(50):s1520.

[18] Eack SM, Newhill CE. Psychiatric symptoms and quality of life in schizophrenia: a meta-analysis. Schizophr Bull 2007;33(5):1225-37. 
[19] Fitzgerald PB, Williams CL, Corteling N, Filia SL, Brewer K, Adams A, et al Subject and observer-rated quality of life in schizophrenia. Acta Psychiatr Scand 2001;103(5):387-92.

[20] Narvaez JM, Twamley EW, McKibbin CL, Heaton RK, Patterson TL. Subjective and objective quality of life in schizophrenia. Schizophr Res 2008;98(1):201-8.

[21] Priebe S, McCabe R, Junghan U, Kallert T, Ruggeri M, Slade M, et al. Association between symptoms and quality of life in patients with schizophrenia: a pooled analysis of changes over time. Schizophr Res 2011;133(1):17-21.

[22] Phalen PL, Viswanadhan K, Lysaker PH, Warman DM. The relationship between cognitive insight and quality of life in schizophrenia spectrum disorders: symptom severity as potential moderator. Psychiatry Res 2015;230(3):839-45.

[23] Leonhardt BL, Huling K, Hamm JA, Roe D, Hasson-Ohayon I, et al. Recovery and serious mental illness: a review of current clinical and research paradigms and future directions. Expert Rev Neurother 2017;17(11):1117-30.

[24] Roe D, Mashiach-Eizenberg M, Lysaker PH. The relation between objective and subjective domains of recovery among persons with schizophrenia-related disorders. Schizophr Res 2011;131(1):133-8.

[25] Huppert JD, Weiss KA, Lim R, Pratt S, Smith TE. Quality of life in schizophrenia: contributions of anxiety and depression. Schizophr Res 2001;51(2):171-80.

[26] Aleman A, Kahn RS, Selten J. Sex differences in the risk of schizophrenia: evidence from meta-analysis. Arch Gen Psychiatry 2003;60(6):565-71.

[27] Eranti SV, MacCabe JH, Bundy H, Murray RM. Gender difference in age at onset of schizophrenia: a meta-analysis. Psychol Med 2013;43(1):155-67.

[28] Angermeyer MC, Khn L, Goldstein JM. Gender and the course of schizophrenia: differences in treated outcomes. Schizophr Bull 1990;16(2):293-307.

[29] Leung MD, Psych CM. Sex differences in schizophrenia, a review of the literature. Acta Psychiatr Scand 2000;101(401):3-38.

[30] Bengtsson-Tops A, Hansson L, Sandlund M, Bjarnason O, Korkeila J, et al. Subjective versus interviewer assessment of global quality of life among persons with schizophrenia living in the community: a nordic multicentre study. Qual Life Res 2005;14(1):221-9.

[31] Kravetz S, Faust M, Dasberg I. A comparison of care consumer and care provider perspectives on the quality of life of persons with persistent and severe psychiatric disabilities. Psychiatr Rehabil J 2002;25(4):388.

[32] Kusel Y, Laugharne R, Perrington S, McKendrick J, Stephenson D, StocktonHenderson J, et al. Measurement of quality of life in schizophrenia: a comparison of two scales. Soc Psychiatry Psychiatr Epidemiol 2007;42 (10):819-23.

[33] Doyle M, Flanagan S, Browne S, Clarke M, Lydon D, Larkin C, et al. Subjective and external assessments of quality of life in schizophrenia: relationship to insight. Acta Psychiatr Scand 1999;99(6):466-72.

[34] Hayhurst KP, Massie JA, Dunn G, Lewis SW, Drake RJ. Validity of subjective versus objective quality of life assessment in people with schizophrenia. BMC Psychiatry 2014;14(1):365.

[35] Hasson-Ohayon I, Roe D, Kravetz S, Levy-Frank I, Meir T. The relationship between consumer insight and provider-consumer agreement regarding consumer's quality of life. Community Ment Health J 2011;47(5):607-12

[36] Ofir-Eyal S, Hasson-Ohayon I, Bar-Kalifa E, Kravetz S, et al. Agreement between clients with schizophrenia and mental health workers on clients' social quality of life: the role of social cognition and symptoms. Psychol Psychother-T 2017;90(2):125-37.

[37] Roe D, Gelkopf M, Gornemann MI, Baloush-Kleinman V, Shadmi E. Implementing routine outcome measurement in psychiatric rehabilitation services in Israel. Int Rev Psychiatry 2015;27(4):345-53.

[38] Gelkopf M, Pagorek-Eshel S, Trauer T, Roe D. Routine outcome measurement in mental health service consumers: who should provide support for the selfassessments? Eval Program Plann 2015:50:43-6.

[39] Weiser M, Werbeloff N, Dohrenwend BP, Levav I, Yoffe R, Davidson M. Do Psychiatric registries include all persons with schizophrenia in the general population? A population-based longitudinal study. Schizophr Res 2012;135 (1):187-91.

[40] Rabinowitz J, Slyuzberg M, Ritsner M, Mark M, Popper M, Ginath Y. Changes in diagnosis in a 9-year national longitudinal sample. Compr Psychiatry 1994;35 (5):361-5.

[41] Weiser M, Kanyas K, Malaspina D, Harvey PD, Glick I, Goetz D, et al. Sensitivity of ICD-10 diagnosis of psychotic disorders in the Israeli national hospitalization registry compared with RDC diagnoses based on SADS-L. Compr Psychiatry 2005;46(1):38-42.

[42] Levine SZ, Lurie I, Kohn R, Levav I. Trajectories of the course of schizophrenia: from progressive deterioration to amelioration over three decades. Schizophr Res 2011;126(1):184-91.

[43] Ullman VZ, Levine SZ, Reichenberg A, Rabinowitz J. Real-world premorbid functioning in schizophrenia and affective disorders during the early teenage years: a population-based study of school grades and teacher ratings. Schizophr Res 2012;136(1):13-8.

[44] Priebe S, Huxley P, Knight S, Evans S. Application and results of the manchester short assessment of quality of life (MANSA). Int J Soc Psychiatry 1999;45(1):712.

[45] Tabachnick BG, Fidell LS. Using multivariate analysis. 2001.

[46] Schwarz G. Estimating the dimension of a model. Ann Stat 1978;6(2):461-4

[47] Furukawa TA, Levine SZ, Tanaka S, Goldberg Y, Samara M, Davis JM, et al. Initial severity of schizophrenia and efficacy of antipsychotics: participant-level meta-analysis of 6 placebo-controlled studies. JAMA Psychiatry 2015;72 (1):14-21.

[48] Samara MT, Goldberg Y, Levine SZ, Furukawa TA, Geddes JR, Cipriani A, et al. Initial symptom severity of bipolar I disorder and the efficacy of olanzapine: a meta-analysis of individual participant data from five placebo-controlled studies. The Lancet Psychiatry 2017;4(11):859-67.

[49] Hazewinkel M. Point of inflection. Encyclopedia of mathematics. .

[50] R Core Team. The R project for statistical computing Available at: www.Rproject.org/.Accessed. 2014.

[51] Bates D, Maechler M, Bolker B. Lme4: linear mixed-effects models using S4 classes. R package version 0.999999-0 [computer software]. Retrieved from rproject.org website:. 2012. http://CRAN.Rproject.org/package0lme4.

[52] Harris MJ, Cullum CM, Jeste DV. Clinical presentation of late-onset schizophrenia. J Clin Psychiatry 1988;49(9):356-60.

[53] Häfner H, Hambrecht M, Löffler W, Munk-Jørgensen P, Riecher-Rössler A. Is Schizophrenia a disorder of all ages? A comparison of first episodes and early course across the life-cycle. Psychol Med 1998;28(2):351-65.

[54] Häfner H. Onset and early course as determinants of the further course of schizophrenia. Acta Psychiatr Scand 2000;102(s407):44-8.

[55] Häfner H, Maurer K. Early detection of schizophrenia: current evidence and future perspectives. World Psychiatry 2006;5(3):130.

[56] Häfner H, Maurer K, Löffler W, Hambrecht M, Schultze-Lutter F. Modeling the early course of schizophrenia. Schizophr Bull 2003;29(2):325.

[57] Häfner H, Maurer K, Löffler W, Riecher-R A. The influence of age and sex on the onset and early course of schizophrenia. Br J Psychiatry 1993;162(1):80-6.

[58] Vinokur D, Levine SZ, Roe D, Krivoy A, Fischel T. Age of onset group characteristics in forensic patients with schizophrenia. Eur Psychiatry 2014;29 (3):149-52.

[59] Levine SZ, Bakst S, Rabinowitz J. Suicide attempts at the time of first admission and during early course schizophrenia: a population based study. Psychiatry Res 2010;177(1):55-9.

[60] Rotstein A, Roe D, Gelkopf M, Shadmi E, Levine SZ. Quality of life disparities between persons with schizophrenia and their professional caregivers: network analysis in a national cohort. Schizophr Res 2018 In Press.

[61] Strauss JS, Carpenter WT, Nasrallah AT. How reliable is the psychiatric history? Compr Psychiatry 1978;19(3):213-9.

[62] DeLisi LE, Goldin LR, Maxwell ME, Kazuba DM, Gershon ES. Clinical features of illness in siblings with schizophrenia or schizoaffective disorder. Arch Gen Psychiatry 1987;44(10):891-6.

[63] DeLisi LE, Hoff AL, Schwartz JE, Shields GW, Halthore SN, Gupta SM, et al. Brain morphology in first-episode schizophrenic-like psychotic patients: a quantitative magnetic resonance imaging study. Biol Psychiatry 1991;29 (2):159-75.

[64] Ho BC, Andreasen NC, Flaum M, Nopoulos P, Miller D. Untreated initial psychosis: its relation to quality of life and symptom remission in first-episode schizophrenia. Am J Psychiatry 2000;157(5):808-15.

[65] Hastrup LH, Haahr UH, Jansen JE, Simonsen E. Determinants of duration of untreated psychosis among first-episode psychosis patients in Denmark: a nationwide register-based study. Schizophrenia Res 2018;192:154-8.

[66] Kay SR, Fiszbein A, Opfer LA. The positive and negative syndrome scale (PANSS) for schizophrenia. Schizophr Bull 1987:13(2):261. 